\title{
Negative critical waves in business relationships: an extension of the critical incident perspective
}

Bo Edvardsson, Christian Kowalkowski, Tore Strandvik and Päivi Voima

\section{Linköping University Post Print}

\section{Tweet}

N.B.: When citing this work, cite the original article.

Original Publication:

Bo Edvardsson, Christian Kowalkowski, Tore Strandvik and Päivi Voima, Negative critical waves in business relationships: an extension of the critical incident perspective, 2014, The journal of business \& industrial marketing, (29), 4, 284-294.

http://dx.doi.org/10.1108/JBIM-08-2013-0159

Copyright: Emerald

http://www.emeraldinsight.com/

Postprint available at: Linköping University Electronic Press

http://urn.kb.se/resolve?urn=urn:nbn:se:liu:diva-106052 


\section{Negative critical waves in business relationships:}

\section{an extension of the critical incident perspective}

Bo Edvardsson*, Christian Kowalkowski**, Tore Strandvik***, Päivi Voima ${ }^{* * * *}$

CTF-Services Research Center, Karlstad University, Karlstad, Sweden

$* *$

Centre for Relationship Marketing and Service Management (CERS), Department of Marketing, Hanken School of Economics, Helsinki, Finland and

Department of Management and Engineering, Linköping University, Linköping, Sweden

***Tore Strandvik

Centre for Relationship Marketing and Service Management (CERS), Department of Marketing, Hanken School of Economics, Helsinki, Finland

****Päivi Voima

Centre for Relationship Marketing and Service Management (CERS), Department of Marketing, Hanken School of Economics, Helsinki, Finland

Corresponding author: christian.kowalkowski@hanken.fi 


\section{Abstract}

Purpose

This study aims to extend understanding of business-to-business relationship dynamics by introducing and discussing the phenomenon of a 'negative critical wave' (NCW), defined as a disturbance in a relationship that emerges and develops within or beyond individual working relationships.

\section{Design/methodology/approach}

The dynamics of working relationships in two manufacturing firms in Finland and Sweden were studied by analysing the narratives of unstructured personal interviews with 16 middle managers and 14 operational executives, who recalled experiences of relevant situations over three years, with emphasis on unexpected disturbances, challenges and problems.

Findings

Respondents discussed 77 NCWs, the development and effect of which proved to depend upon the original 'locus', 'magnitude' and 'amplitude', and embedded 'energy'. Waves could be distinguished as: 'silent compact', 'silent extensive', 'intense compact' or 'intense extensive'.

\section{Research limitations/implications}

The wave metaphor for relationships dynamics, consistent with but distinct from established notions of 'critical time' and 'critical incidents' and the associated classification system are a useful starting point for further research into the phenomenon. Though the qualitative methodology achieved richness, the small sample and restricted scope place limits on the objectivity and generalisability of the findings.

\section{Practical implications}

The NCW framework offers strategists and managers a holistic understanding of the dynamic process of criticality, synthesising the complexities of relationship dynamics and pointing to ways in which to absorb the energy of negative waves.

Originality/value of the paper

More is now known about the domino effects of critical incidents in internal and external businessto-business relationships.

Keywords: Business-to-business, working relationships, critical incidents, relationship dynamics, verbatim narratives.

Paper type: Research paper 


\section{INTRODUCTION}

The Critical Incident Technique (CIT) was originally developed by Flanagan (1954) as suite of procedures to identify critical determinants of effective and ineffective behaviour among US Air Force pilots, but has since been widely used in services marketing to identify critical factors in the customer's service experience, perceived service quality, and the dynamics of customer relationships. Reviews of the literature of CIT, up to 2004, are to be found in Bitner et al. (1990), Gremler (2004), Lockshin and McDougall (1998) and Roos (2002). A critical incident has been defined as an event that deviates, either positively or negatively, from what is normal or what customers expect (Gremler, 2004). Most of the empirical studies of critical incidents have been carried out in the context of B-to-C marketing, but related concepts as 'critical events' (Havila and Salmi, 2000; Tidström and Hagberg-Andersson, 2012) and 'precipitating events' (Olkkonen and Tuominen, 2008; Tähtinen and Halinen 2002) have also been used to analyse the dynamics of B-toB customer relationships.

Previous research has shown that incidents or events reported by customers to be critical were not in fact so, in the sense of resulting in a change in the nature of their relationship with the business (Edvardsson and Strandvik 2002; Gremler 2004). Furthermore, the focus has been on causes of individual incidents (Edvardsson, 1998) or triggers (Roos 1998; Voima 2001) and to some extent on their outcomes (Edvardsson and Strandvik, 2009). However, very little is known about the turbulence and domino effects within and beyond the focal relationship, initiated by negative critical incidents. This paper therefore extends the focus beyond individual incidents and introduces the notion of a 'critical wave': a disturbance in a relationship, which emerges and enlarges within or beyond individual relationships. It is the central construct of a new framework for analysis of customer relationships, which we call the 'negative critical wave' (NCW) model.

Studies of CIT in the B-to-B context have traditionally aimed to capture transactions, interactions or incidents that have a significant effect on perceptions and behaviours in the relationship between a seller and a buyer. Critical incidents, specifically, are exceptional or turbulent situations in which the sensitivities of the parties are heightened (Holmlund and Strandvik, 2005). Since they affect the nature of relationships, they can be used to understand relationship dynamics (Edvardsson 1989, 1992; Stewart 1998).

Recent research on critical incidents in B-to-B contexts has found that changes in business relationships are often the outcome of a long and complex process (Edvardsson and Strandvik 2009; Edvardsson et al. 2008; Holmlund 2004). To understand how and why relationships develop and change, it might be more appropriate to adopt a unit of time as a unit of analysis rather than 
individual incidents, which are isolated events in time. Although several studies of business relationships confirm this view, such as those by Dubois et al. (2003), Flint et al. (2002), Halinen and Tähtinen (2002), Havila and Wilkinson (2002), Tähtinen (2002), and Tikkanen and Alajoutsijärvi (2002), few researchers have shown interest in the distribution of critical incidents over time, and the effects on the buyer's and seller's business systems.

Edvardsson and Strandvik (2009) propose a process-based view for studying critical incidents in a relationship, introducing the concept of 'critical time' as a period of stress and raised sensitivity, triggered by an incident, which may potentially transform the relationship. The traditional incidentbased view thus becomes an embedded part of critical time. Similarly, a study of negative critical incident processes in business relationships by Voima (2001) shows that the perceived level of criticality plays the key role in the development of the process, rather than the incident as such. Thus, changes in business relationships happen for different reasons and there may be a variety of domino effects.

Some theoretical approaches, frameworks and empirical studies focus on customer relationship dynamics beyond individual incidents: for example, studies of the trigger effects on customers' learning experience (Edvardsson et al., 2002), stress in B-to-B relationships (Holmlund and Strandvik, 2005a), the management of negative incidents in business relationships (Holmlund and Strandvik, 2005b), the analysis of B-to-B relationships (Strandvik and Holmlund, 2008), the "netquake" approach to network dynamics (Dahlin et al., 2005) and the initiation of B-to-B relationships (Edvardsson, Holmlund and Strandvik, 2008). However, understanding remains sparse of the dynamics within B-to-B relationships, focusing on the analysis of multiple events and the responses of actors in the system to incidents resulting in systemic, process-based changes.

Central aspects of criticality that are generally missing in traditional studies of critical incidents are the 'amplitude' and 'magnitude' of the critical wave, defined here as respectively its metaphorical height and breadth, which determine the turbulence it causes in the user-supplier relationship and its influence on other working relationships within the business system in general. However, not all incidents that would normally be defined as critical are in fact critical for the relationship, in the sense that they would result in a lasting or irreversible change in it (Edvardsson and Strandvik 2000). In order to better understand turbulence and criticality in relationships, the 'energy' generated by the wave is assumed to have special explanation power. Accordingly, we define 'negative critical incidents' as events with the energy needed to change the relationship. In this paper, we will not focus explicitly on outcomes but argue that they are always dynamic and embedded in the 'critical wave'. 
To capture the nature of relationship dynamics, we will extend the conceptualisation of critical times (Edvardsson and Strandvik 2009) and consider negative critical waves of relationship turbulence - long and wind-blown or short and sudden but all deviating far from stability and equilibrium - travelling through space and time. The focus is on how this negative critical wave develops, thereby driving change in the customer-provider relationship, in other relationships, and in the whole business system.

The aim of this paper is to develop the NCW framework and thus extend the understanding of relationship dynamics by analysing the origin and development of negative critical waves. We will use the energy as our focus and the waves as the metaphor. More specifically, the concept of critical times (Edvardsson and Strandvik 2009) is broadened to that of negative critical waves, through the NICIPA (Negative Internal Critical Incident Process Analysis) technique (Voima 2001), by exploring criticality in business relationships.

The paper is structured as follows. First the critical incident literature is reviewed in relation to relationship dynamics in a B-to-B context, and the NCW metaphor introduced. After discussion of the research methodology, the NCW framework is applied in an empirical study, the results of which are presented in the form of a NCW model. Finally, the findings and research contributions are discussed, managerial implications examined, research limitations identified, and suggestions offered for further research.

\section{THEORETICAL FRAMEWORK}

The dynamics of working relationships have been studied in research into, for example: their inception (Chen, 2006; Edvardsson et al., 2008; Wu and Cavusgil, 2006); their fading or ending (Geersbro and Ritter, 2013; Havila and Wilkinson, 2002; Michalski, 2004; Tähtinen and Halinen, 2002); and switching (Keaveny 1995; Marshall et al. 2011; Roos 1999; Wieringa and Verhoef (2007). The terminations of some business relationships "shake the ground far away from ending business relationship, whereas some business relationships end without any effect on the surrounding business network" (Dahlin et al., 2005, p. 2). However, issues that have not been explicitly dealt with are those related to the development of perceived criticality (that is, energy), the impact of an incident, the origin of the disturbance, and the forces that come into play to establish, change or dissolve a customer relationship. Furthermore, the effects of relationship dynamics beyond the customer-provider relationship have rarely been empirically studied. 
It has been argued, for example by Edvardsson and Strandvik (2009), that a focus on separate incidents only does not explain relationship dynamics sufficiently and that a wider approach is therefore needed. One such study, by Voima (2001), has shown that the energy linked to incidents plays a key role in the development of the negative critical incident process rather than the incidents themselves. Strandvik and Holmlund (2008) suggest a technique, which they label Negative Incident Mapping, to explore and map negative incidents in business-to-business relationships, generating results on the incidents, individual relationships, and portfolio of customer relationships. Their technique has a wider scope that traditional critical incident studies but does not explicitly include criticality as a dynamic construct in the analysis.

A study of business customers' relationships with a particular hotel by Edvardsson and Strandvik (2000) found that only a few incidents redirect customers' evaluations of the relationship and influence their future behaviour. The main conclusion was that many incidents that are reported as critical by the respondents did not seem to have had an effect on the relationship with the hotel. Rather, the effects of critical incidents are the result of a combination of factors associated with the situational and temporal context of the relationship, and may not result in switching or other negative business effects. The reason could be that the energy is not enough to drive change. Thus, to understand negative critical incidents and their business consequences, the amplitude and magnitude of the disturbance need to be taken into account.

Similarly, Edvardsson and Strandvik (2009) define the concept of critical time as a period of raised sensitivity and stress in a relationship, which may change the nature of the relationship. It is not necessarily a single event, but may be a continuing situation. It consists of three elements embedded in a temporal and situational context: the initial state of the relationship, the dynamics and duration of critical time, and the outcome state of the relationship. The critical time perspective thus embraces time as well as the context within the relationship, the external business environment and the internal organizational environment. It thereby reframes the traditional critical incident perspective by widening the scope to include dimensions related to time and context. Its originators argue that focusing on isolated incidents is not enough if the aim is to identify and understand dynamics in business relationships, though they did not pay explicit attention to the energy of the process.

\section{The negative critical wave construct}

Grounded in the work by Voima (2001), focusing on energy originating in negative critical incidents, and on the critical time concept (Edvardsson and Strandvik, 2009), we develop a theoretical framework for the negative critical wave phenomenon, to deepen understanding of the 
mechanisms in business relationship dynamics. Explicit attention is paid not only to the amplitude and magnitude of the energy embedded in negative critical waves, as already defined, but also to their 'locus': that is, where in the organisational structure their effects first become apparent. The wave analogy has previously been applied to supply chain dynamics (Hines et al. 2000) and we argue that the concept of a 'critical' wave will deepen the understanding of relationship dynamics. The wave metaphor furthermore recalls the established 'river' metaphor in strategic management, which emphasises process and constant forward motion, implying that managers and other decisionmakers need to relate their decisions to different timing (Lamberg and Parvinen 2003). It may also be helpful in gaining further insights into criticality and the reasons behind relationship dynamics in B-to-B settings, beyond individual relationships, with important effects on strategic business units and networks within a business system, and also on factors beyond the strategic business unit.

The wave-building process starts when one or several actors observe or sense a significant deviation from what is perceived to be normal and what is expected, which might be manifested as a disturbance, challenge or problem in the relationship. The negative critical wave often occurs in the context of multiple relationships, in which the actors involved give energy to the wave, or take energy out of it. As earlier research shows, the timescale may vary from short and straightforward incidents to the equivalent of a long cycle of wind-driven waves (Edvardsson and Strandvik 2001; Holmlund 2001, 2004; Tähtinen 2002; Voima 2001). However, whereas there have been previous studies of overall relationship energy, for example by Havila and Wilkinson (2002), they have not specifically addressed energy related to the magnitude and amplitude of disturbances in relationships - that is, in negative critical waves.

Negative critical waves are thus not objective processes; instead, they are social and personal constructions, which are dynamic, contextual, temporal, spatial, psychological and highly affective in nature. The impact they may have on the customer-provider dyad and other business relationships is not only individual but often collective and shared. The parties' experiences and interpretations of the negative critical waves shape the relationship between customer and provider and simultaneously, several other business relationships. At the same time, this determines the amplitude and magnitude of the wave. When relationships are highly integrated, it may easily spread and influence not only the customer-provider dyad but also other business relationships within the firm and between firms. The embedded nature of the negative critical wave is therefore central to this study, as opposed to more traditional studies, using the critical incident technique without attention to context-related factors. 
In this paper, the conceptualisation of a negative critical wave includes influence from its locus, magnitude and amplitude. The effects of a wave vary in duration from short-term to long-term turbulence, in the spatial dimension from a local issue of limited extent to a more extensive issue in which layers of the seller's and buyer's organizations beyond the initial actors become involved. Waves also vary in the intensity of their affective impact, from weak to strong, and in the extent to which their effects are communicated to the affected parties (Edvardsson and Strandvik 2009; Voima 2001). The influence on the consumer-provider relationship and on other business relationships within and between the firms, including effects in the business system in general, is a function of amplitude and magnitude as well as the locus of the negative critical wave. Thus, the framework presented in this paper is developed around energy as a function of the negative critical wave's locus, amplitude and magnitude.

\section{METHODOLOGY}

An exploratory empirical study was carried out in the pulp and paper and engine manufacturing industries in Finland and Sweden. Numerous customer-supplier relationships were studied. Data were collected by means of unstructured interviews with 30 individuals, of whom 16 were middle managers and 14 at a lower organizational level. Respondents were asked to recall their experiences of relevant situations over the past three years, each interview opening with a question concerning expected or unexpected disturbances, challenges and problems encountered in customer-supplier relationships. The expected response mode was 'story telling', which would build a description of the emergence and formation of negative critical waves. The resulting narratives were constructions of reality with respect to what the respondents remembered about the locus, amplitude, magnitude and energy of a given negative wave.

Respondents were invited to contribute as many narratives of negative critical waves as they wished. The result was 77 negative critical wave episodes, 42 recalled by the lower-level employees and 35 by the middle managers. The interviews were carried out at the respondents' workplace, each lasting between one and a half and two hours. They were tape-recorded and transcribed. The narratives were individual views of a critical wave, as recalled at the time of the interview. They are therefore not represented as being the 'objective truth' of what actually happened, but rather a reflection of an experience as remembered and interpreted. The starting point of this methodological design is that reality is socially constructed and experienced at both the individual and collective level. Human beings construct the world around them, and are themselves constructions of it through the agency of social structures and forces. They produce and reproduce social structures in 
their actions, values, and language, among other ways. Actors in the buyer-supplier relationships 'deconstruct' such phenomena as working relationships and critical waves, a process which in turn modifies and 'reconstructs' them as participants in those phenomena. What this means, in effect, is that managers act on the basis of their interpretations of problems and challenges in relationships, not of what actually happened. As Gergen (1994, p. 49) puts it, "words take on their meaning only within the context of on-going relationships". This view of the personal nature of negative critical waves is consistent with the research approach taken by Hackley (1998, p. 125) who asserts that it "takes subjective reports of events, emotions and cognition to be multifaceted constructions, which can be interpreted on many levels".

\section{RESULTS}

In this section, we first describe the formation of a negative critical wave (henceforth 'NCW'), in terms of its locus, amplitude, magnitude and energy. Second, we offer a categorisation of NCWs. Third, based on our exploratory longitudinal comparative analysis of 77 real-world NCWs, four distinct categories are described and discussed in detail.

\section{Categorization of negative critical waves}

The process of formation of a negative critical wave is illustrated in Figure 1. Analysis of respondents' narratives suggested three key determinants of the energy of a wave. First, its locus, the organisational location at which its existence became apparent to respondents, was seen to have influenced the subsequent form and energy of the wave. In the figure, the amplitude dimension corresponds to respondents' description of the 'intensity' of a NCW, expressed in terms of its emotional impact on their work and the extent to which its existence was communicated within the organisation. The narratives also provided evidence for the existence of spatial and temporal differences among NCWs, which are shown in Figure 1 as the magnitude dimension. We thus concluded that the total 'energy' of a wave is a function of its locus, amplitude and magnitude. To explore the dynamics of the typical NCW, each of the four elements identified in the empirical narratives is next defined and discussed in turn and in detail.

\section{Take in Figure 1}

\section{LOCUS}


The locus of the NCW was found to be important for the understanding of its development and consequences, which confirms the findings of previous studies of critical incident technology, that the initial state of the relationship is a key concept (Roos 1999; Holmlund and Strandvik 2005b; Voima 2001; Edvardsson and Strandvik 2009). The analysed narratives showed that individual waves had various loci, and therefore differing influences on magnitude, amplitude and energy. It was also clear that the relationships within which they emerged could be categorised as stable, unstable or turbulent. Our analysis further concluded that magnitude and amplitude varied with the organizational level at which the wave arose, the two of which identified in our study were defined as operational and middle management. The incident that initiated a NCW, here referred to as the generator, was found to be connected to technical or social aspects of the relationships affected. The former applies when the wave is generated by a disturbance at the core of the value-creation process, the latter when the origin is a disruption of social interaction or awareness of a lack of trust or respect.

\section{MAGNITUDE}

The magnitude of the NCWs recalled by the respondents proved to vary in two key respects: temporal and spatial. Whereas some built up into comparatively long processes, others faded away in a short period of time. Similarly, some waves remained focused within a narrow area of the organisation and influencing relationships only in the locus in which they originated, while others had a broad spread, making their influence felt in multiple relationships or at different levels of the organisation, or both, within and between the customer and supplier.

\section{AMPLITUDE}

Two distinct types of amplitude were embedded in the notion of a NCW: affective and communicative. Respondents expressed emotions that can be categorised on the basis of their intensity, as in studies by Derbaix and Pham (1991), Richins (1997), Edwardson (1998), Roos (1999) and Voima (2001), on a continuum from weak to strong. The weak end corresponded to reports of having been upset, irritated or dissatisfied, whereas a strong affective response would be anger, humiliation, frustration, hurt feelings, and sadness. The communicative component of a wave's amplitude comprised features of both word-of-mouth communication and complaining behaviour, recognising the operation of formal and informal communication within and across organisational hierarchies. Drawing upon earlier research (Richins 1983, 1987; Singh 1990; Blodgett and Tax 1993) such communication was first classified as present or absent. If there was relevant communication relating to the existence and development of a $\mathrm{NCW}$, it was classified as low-level or high-level, according to the number of people who were told about the related incident. 


\section{ENERGY}

The energy of a NCW is the net outcome of its locus, amplitude and magnitude, and may intensify as part of the generative process rather than remaining constant. The effects and consequences depend on the energy a wave contains, absorbs or loses. Analysis of the respondents' narratives showed that some waves possessed a high level of intrinsic energy while others had very little, and that some gained energy and momentum while others faded or died. In some cases, domino effects increased the magnitude and amplitude of the wave. In others, factors and actors absorbed some of the intrinsic energy, for example by mobilising increased internal support to resolve the situation, and thereby decreased magnitude and amplitude. This empirically grounded categorisation of the factors influencing the life of a negative critical wave is summarised in Table 1.

\section{Take in Table 1}

\section{A typology of negative critical waves}

The analysis generated the four distinct NCW categories shown in Figure 2: silent compact wave; silent extensive wave; intense compact wave; and intense extensive wave. These terms are defined later in this sub-section, and respondents' narratives are selectively presented as an aid to understanding the flow of these four types.

Take in Figure 2

The locus of a wave was found to influence its development in several ways. When the external or internal working relationship within which the wave emerged was relatively stable, the magnitude and intensity of the wave remained low. If it could be characterised as unstable or turbulent, and was coloured by a history of problems and challenges, the NCW was more intense and its magnitude wider in temporal and spatial terms. Waves formed at lower organizational levels exhibited wider magnitude and higher amplitude, reflected in their frequently strong temporal and spatial impact.

When a NCW was generated by a technical disturbance, its amplitude remained low in affective and communicative terms. If internal or external social forces generated it, the amplitude was much 
higher on both dimensions. Waves were also given energy by comments and complaints concerning the disturbances or challenges in the relationship. Waves with narrow magnitude and low amplitude seemed to indicate a less negative influence on the relationship, whereas a wider magnitude and greater amplitude implied higher affective and communicative intensity, and led to a more negative influence. Table 2 presents a summary of the characteristics of the four varieties on NCW, which are next discussed and explored in detailed.

\section{Take in Table 2}

\section{SILENT COMPACT WAVE}

Silent compact waves appeared to be characterised by a rather narrow magnitude and low amplitude, which did not have the capacity to generate permanent change in the relationship. They typically had one of two origins. The first sub-category emerged in relationships that were stable and had a history of working well. That stability absorbed energy from the wave, which remained 'silent', in the sense that it was not communicated openly. The magnitude of the wave depended on the organisational context from which it emerged. Of a total of 13 silent compact waves described, nine had been experienced by operational personnel and four by middle managers. Those reported by the former had been generated by technical disturbances at the core of the value-creating process. The silent compact waves discussed by respondents with a wider perspective on the total process, such as middle managers, had a narrow magnitude both temporally and spatially. The scale of the actors' understanding of the situation and the scope of their potential to take action seemed to absorb the energy of the wave. Respondents in more senior positions demonstrated the ability to embed challenges or problems in a broader context, which absorbed energy to the extent that a wave of this type never grew into a more intensive or extensive form. It did not spread spatially and remained temporally short-term, fading away after a short lifespan.

The following statement by a middle manager exemplifies the absorption of the energy of a NCW:

"We have a history of working well together. If a problem occurs, we tackle it immediately. Last week a report was done a little hastily, which led to one unnecessary curve in the process. These problems are part of the job, and after a few days they are history, so I don't take them personally. This didn't turn into anything serious that couldn't be fixed with some extra work." 
Employees at lower organizational levels generally reported experience of the second type of silent compact wave, which had emerged in inter-firm and intra-firm relationships of a more unstable nature. Those were more long-term, but did not extend spatially beyond the group of employees initially affected. They were initiated by a disruption of social interaction among colleagues, for example by a negative tone of voice or abusive language. Though these waves had a strong affective impact, their magnitude remained narrow because the respondents did not want to talk about the incidents with colleagues or management, and the energy therefore did not reach above the surface of the wave. The long-term consequence was decreased trust and respect for the other party.

A respondent at the operational level put it this way:

“The relationship hasn't always been so easy, so when I was instructed to fix a situation in a specific way I was really annoyed. The problem was not the content but the bossy tone of the other party's orders. Every time I'm in touch with the other party something different is in the air. I think it is a question of respect. You have to earn respect; it doesn't grow on trees."

\section{SILENT EXTENSIVE WAVE}

Silent extensive waves developed below the surface, and advanced in a silent fashion both spatially and temporally. They nevertheless constituted a force capable of influencing many relationships and the business network in general, often permanently. The relationships affected varied from stable to unstable. The waves typically emerged at the operational level (11 out of 13 cases), having been generated by technical disturbances, which had their locus in everyday processes and communication-related phenomena, such as differences in the working procedures and practices of different shifts. Technical challenges and communication structures also contributed to the generation of these waves. Since the affective and communicative levels were low, the wave appeared to advance gradually in silence and had often influenced the relationship dramatically before it was noticed. An analogy might be the tsunami, which is invisible in deep water because of its low amplitude and long wavelength, but can grow to disastrous proportions. Similarly, silent extensive waves initially exhibit low energy before accumulating and spreading insidiously under the surface of numerous relationships. Due to the relatively complex organizational contexts in which they often occur, they too may not be detected until they have made a significant impact, often at some distance from the locus at which they originated in the relationship network. Thus, the 
magnitude of the silent extensive wave is wide and its effects are continuous across its total extent. The groups of employees initially affected do not necessarily feel the effect more strongly, but the extensive influence of the wave is seen in the manner in which its negative energy spreads to many other groups, influencing their relationships spatially and temporally.

Two operational-level respondents explained relevant situations they had experienced as follows:

"The other shift had made an adjustment to the machine that we weren't aware of. In these situations, if the quality of the product doesn't fulfil the quality requirements, that affects not just our job but also our customers and their customers. A minor mistake can cause the whole process to collapse, and in the end it's the final customer who suffers, which again costs money."

“The communication system isn't well enough developed for the suppliers to register the changes they make. In some cases, the machine just stops working and we don't know why. I know it's just part of our job, but it's like playing dominoes. If somebody puts theirs down carelessly, the rest of the process can't stop a catastrophe from happening. We know this is problematic, but the extent of the chaos surprises us every time."

\section{INTENSE COMPACT WAVE}

Compared to silent compact waves, the intense compact wave is characterised by a higher level of communicative and affective energy. The working relationship was emotionally loaded, experienced as being unstable or turbulent, and coloured by challenges in its history. Of 29 intense compact waves identified, 26 had been experienced by middle managers. Their magnitude was narrow and, although they were characterised by higher emotional amplitude, the extent of the turbulence and the communication related to the disturbance were both limited. The impact of an intense compact wave appeared to be influenced by the circumstances of its generation. If its origin was grounded in a technical disturbance, which in most cases was connected to problems in everyday communication processes or the circumventing of hierarchies and procedures, such disturbances were experienced as so 'everyday' that middle managers did not react to them. Although the influence of these waves was long-term, their impact remained beneath the surface as continuous and silent dynamics. The influence on other relationships was more technical in nature, but seemed to be in the background of the experience: like a wave that everybody knows will 
continue its journey but nobody is quite sure to where. The impact was temporally strongest for waves with their original locus in a social disturbance. Most of these waves and emerged through experiences in which a respondent felt that his or her competence had been challenged. These critical waves influenced the relationship more extensively and were of a long-term, relationshipchanging nature.

Two comments by middle managers illustrate the nature of intense compact waves:

$$
\begin{aligned}
& \text { "Based on a minor technical problem, the supplier said in front of the whole } \\
& \text { team that we couldn't be trusted. I was really upset, almost furious, but I } \\
& \text { didn't say a word. But it's difficult to respect them if they operate in this } \\
& \text { way. These things stay beneath the surface, somehow, and they stay there } \\
& \text { for some time. We do our work as well as we can, but the general 'drive' is } \\
& \text { maybe decreased to some extent." } \\
& \text { "Information that I needed had bypassed me, although the new process } \\
& \text { manuals clearly say it has to come through me. It's frustrating that people } \\
& \text { don't respect organisational hierarchies since, in this case, many things } \\
& \text { could have gone wrong. Fortunately, we could fix the situation within a } \\
& \text { short period of time and there were only some minor delays reported in the } \\
& \text { rest of the process, which wasn't that severe. I know I should have taken } \\
& \text { this problem up in regular meetings, but these problems are somehow } \\
& \text { forgotten in the daily routine until they pop up again in one form or } \\
& \text { another." }
\end{aligned}
$$

\section{INTENSE EXTENSIVE WAVE}

The intense extensive waves described by respondents were the most dramatic and carried the most energy of the four types of wave. Their origin had often been challenging and unstable, coloured by negative turbulence in the process-related and interpersonal history of the relationship. These waves had their locus typically at lower organizational levels (21 out of a total of 23) and were generated by both technical and interpersonal disturbances, spreading by virtue of high emotional intensity and communication beyond the groups of employees initially affected. The spatial and temporal consequences were both extensive, so the magnitude of the wave was considerable. A majority of the intensive extensive waves had been generated by on-going challenges and problems of a 
technical nature, often connected to the potential to influence daily business routines and work processes. They were energised by the respondent's sense of inability to influence the outcome. The disturbances that respondents experienced were considered so extensive that a wave with high emotional and communicative impact emerged. It was noteworthy that challenges which at first seemed "easy to fix" gradually expanded into an "experiential storm", allowing the wave to feed on its own energy.

In a minority of cases, lack of respect had been a general experience. In such situations, lack of respect was a collectively experienced problem, which resulted naturally in high levels of communication and emotional intensity, thereby initiating an energising process. These waves were reported to have influenced motivation at work and the ability to co-operate and undertake initiatives. The impact of an intense extensive wave was always long-term at both the technical and interpersonal level.

A middle manager and operational employee recalled intense extensive waves in these words:

"We've had some problems with quality. Actually, on all products that we have delivered ... To a certain extent, we've tried to improve the situation but it's difficult because we're a large company. This has led to a situation where the customer 'cries louder and louder' and that's now on the agenda of our top management team, and everyone knows it's not good. [As a result] we now have a quality control manager working full time on this issue ... It's very difficult. I go there almost every second week when they find some new problems, but at the same time they know that leads to something positive... It has definitely led to a stronger relationship, since we have almost daily contact ...I don't think [the customer] wants to go through this process with another supplier."

"The dry part [of the paper machine] is otherwise OK but the ropes often brake. We've told them about this over and over again, but nothing happens. It makes me angry that I have to do a bad job, which affects the other parts of the process quite dramatically, which irritates everyone. However, it's out of my control.” (Operational level)

\section{Origin of critical waves}


The context of change has been recognised as important in many studies: for example, Beverland and Lockshin (2003), Dubois et al. (2003), Edvardsson and Strandvik (2009) and Voima (2001). In line with the last of those, on change in relationship networks, the locus of the NCW was found to influence its formation. The respondents' narratives revealed that the energy level was mainly determined by multiple factors, which formed the conditions under which different types of waves could start to develop. Some of the NCWs had been more visible with respect to their impact on such technical elements in the process as machine failures, delivery delays and the like. However, many were more abstract and invisible, but still created dynamism in the behaviour of the respondents and the business network within which they operated.

The analysis is next deepened to shed more light on the context of critical waves, and the impact it has on the four types of NCWs.

\section{INITIAL STATE}

Waves with the lowest amplitude and least magnitude were found in a stable initial relationship and were experienced by middle managers. The remainder, 68 waves in total, emerged in relationships characterised by instability or historical turbulence. Personnel at lower levels of the hierarchy reported the tallest and broadest waves, with the highest energy levels. Those that arose in turbulent or unstable relationships were the most intensive and exhibited a broad spatial and temporal magnitude. The NCW processes were characterized by their social nature, having their origin in such profoundly negative aspects of interpersonal behaviour as lack of respect. Intense and extensive waves also emerged from turbulent relationships. Being of a more technical and processoriented nature, those arose from disruption of daily business routines. They were emotionally intense and extended widely through communication in the affected organisations.

\section{HIERARCHICAL LEVEL}

The magnitude of a wave was found to vary according to the locus of its origin in the organisation. Of a total of $37 \mathrm{NCW}$ s experienced by middle managers, 30 were defined as compact. Of those only four were silent, while 26 were intense compact. The fact that only 5 critical waves of broader magnitude were reported by middle management, two silent extensive and three intense extensive, suggests that a wider hierarchical and process development seem to limit the magnitude of the wave and absorb energy from the process. Although the incident causing the NCW would be emotionally experienced by middle management as so disturbing that a critical wave emerged, the communicative energy of communication and complaining was absorbed, and the damaging effects of the wave were minimised. Actors in higher hierarchical positions had the ability to set the 
disturbances, challenges and problems in a wider context, thereby absorbing energy from the wave and inhibiting its growth into to more intense and extensive form.

\section{GENERATORS}

Of a total of $76 \mathrm{NCWs}, 47$ were generated by a technical disturbance or challenge at the core of the value-creation process. The remaining 29 resulted from disruption of social interaction or such behavioural phenomena as trust and respect. A clear majority of the NCWs that emerged at a higher hierarchical level were technically generated, suggesting that a higher organizational origin and broader magnitude dilute social disturbances quite effectively. Given that technical disturbances generated both very low and very high waves, of both narrow and wide extent, the energy level seemed to be determined by other factors, such as the origin of the wave. In NCWs caused by technical problems or disturbances arising in a stable relationship, the general energy level remained low: narrow magnitude and low amplitude. On the other hand, if the waves were technically generated in unstable or even turbulent situations, their energy was much higher. High energy became visible when the wave spread and the impact became long-term.

\section{CONCLUSIONS AND RESEARCH CONTRIBUTION}

Based on a review of the relevant literature and 30 in-depth unstructured interviews with practising managers and workers in Finland and Sweden, we have developed a conceptual framework to explain the origin, extent, origin and lifespan of a negative critical wave (NCW). This wave originates at a 'critical incident', and is propelled through time and organisational space by the impetus of its energy. The initial disruption may be the result of negative deviation from the norm, of 'things going wrong', or of the expectations of one or more of the human actors not being met. During the NCW process, the wave's momentum is likely to vary, as energy is added or subtracted by a variety of factors in the system.

Our paper makes two important research contributions. First, it proposes a new conceptualisation of what is termed 'relationships dynamics' in the Scandinavian school of industrial and business-tobusiness marketing, in the form of the NCW framework. The focus is on three characteristics of such a wave: its locus (where it originates), its magnitude (how widely it spreads and how far it travels) and its amplitude (the metaphorical height it reaches, defining the intensity of its effect), and the consequences for the dynamics of the buyer-seller relationship and the business system in general. The concept of a NCW is similar to but different from the notion of 'critical time' described by Edvardsson and Strandvik (2009). That was defined as having a clear beginning and 
ending, and was characterised as being unexpected. In contrast, NCWs may emerge suddenly, silently and unexpectedly, but equally may be anticipated as a product of a turbulent organisational environment and disrupted working relationships. They can furthermore vary in amplitude and magnitude, invading internal and external relationships throughout the business system. One source of the energy in these waves is communication, specifically individuals complaining to one another about the turbulence, disruption, problems or challenges they are experiencing in the working environment.

Our new framework emphasises the importance of the energy level of the NCW. In some circumstances, that may start at a low level and build up while the wave is under way as a result of, for example, inappropriate responses from colleagues and business partners, negative synergy with other incidents and actors, and rumours. In others, one or more influential actors may extract energy from the wave, by other incidents that result in measures to resolve the situation, or by other issues or questions.

The second important research contribution is the identification of four distinct types of NCW, which constitute a useful tool for describing and analysing negative critical waves: silent compact waves, which had low magnitude and amplitude, and low-energy; silent extensive waves, characterised by high magnitude and amplitude; intense compact waves, characterised by low magnitude and high amplitude; and intense extensive waves, which exhibited high magnitude and high amplitude.

Magnitude and amplitude are influenced by the characteristics of the organisational environment in which a wave had its locus: stable, unstable or actually turbulent. Waves originating in stable conditions were the smallest experienced by middle managers, with their narrow reach and low energy. A locus at a higher level of the organisation seemed to absorb some of the energy of a wave, diminishing its magnitude and mitigated the outcome. Those with the greatest amplitude and magnitude originated in turbulent or unstable relationships at the lowest organisational levels and seem unable to absorb all the energy developed. The contingency approach to relationship dynamics embodied in the NCW model is an important addition to previous conceptualisations of criticality (Edvardsson and Strandvik 2000; Voima 2001) and to frameworks and models that have portrayed relationship dynamics in terms of triggers (Keaveny 1995; Roos 1999, Voima 2001), and the factors behind relationship dynamic processes (Edvardsson 1998; Edvardsson and Strandvik 2009). However, prior studies neither distinguish categories of critical process nor explore the domino effects that are developed in our framework. Furthermore, the empirical basis of the NCW model is an extensive series of narratives, capturing rich information on factors relevant to the energy of a 
critical wave, which is not a characteristic of other studies of business-to-business relationship dynamics. We conclude from the analysis of these empirical data that dynamic processes can develop in very different ways.

\section{MANAGERIAL IMPLICATIONS}

The NCW model encapsulates a large number of constituent elements on the basis of which managers can identify, describe and analyse critical waves in the organisation, chart their progress and predict the outcome. A critical wave can evolve in various relationships and influence them to different degrees. The NCW model is a diagnostic tool, in its capacity to identify the relationship contexts in which relationships critical waves most often emerge, which is an important input to strategic management of the consequences. It can be used to assess NCWs from the perspective of their origin, locus, amplitude, magnitude and energy, thereby helping managers to diagnose which relationships are critical and are a breeding ground for the emergence of critical waves. This diagnosis in turn offers opportunities to create appropriate filters that will absorb the wave's energy and diminish its magnitude. The wave metaphor can also be a highly useful tool in management training and education, or internal workshops, helping those who have to cope with the consequences of NCWs to understand the interconnect elements of the model (cf. the service function concept, Kowalkowski, 2011).

As Lamberg and Parvinen (2003) have pointed out, the practical value of metaphors rests critically on the fact that "managerial problems very seldom fall within disciplinary boundaries set out in the academic literature or functional boundaries within organizations" (p. 555). In the case of the NCW metaphor, managerial understanding of relationship dynamics can be strengthened by focusing attention on the entire phenomenon, including its origin, rather than on individual critical incidents only. Doing so will suggest the kind of restructuring needed if NCWs are to be averted in future or their effects at least minimised. The model can thereby act as a communication vehicle, with the potential to facilitate a shared understanding of the phenomenon.

Furthermore, the four wave typologies identified by our study emphasise that it is not so much the individual elements of our conceptual framework that have the explanatory power as the overall energy level of the wave, how that develops, and how it is understood and managed by the various actors involved. Thus the focus should be on analysing the sources and nature of the energy of critical waves in the context of the organisational relationships and wider business system in which 
they are embedded. Some relationships are very stable and may not disintegrate even when the energy level is high; others are much more fragile, and likely to suffer much greater damage. Most importantly, our conceptual framework emphasises the importance of managing change in business relationships, by recognising critical waves at the core of this dynamism. The four different types of wave identified in this study, corresponding to four distinct types of types of relationship which differ in their amplitude and magnitude, provide a foundation on which to base strategic decision-making. From the managerial perspective, it might be less important to exactly know what "actually happened" than to know how the key actors concerned experience the situations and how they respond, in terms of future attitudes, plans and actual behaviour. Furthermore, the most expansive waves (the 'silent extensive' and 'intense extensive' types) both tend to originate in an operational locus, regardless of whether the context is stable, unstable or turbulent and whether the wave generator is of a technical or social nature. Thus, managers should recognize that the potentially most harmful waves often originate at the operational level rather than in a middle management milieu. Organisations should therefore have adequate 'early warning' mechanisms in place to detect their emergence there. However, silent extensive waves in particular may be difficult to discern at an early stage in their progress towards 'tsunami' status.

\section{LIMITATIONS AND FURTHER RESEARCH}

The focus of our study was customer-supplier relationships in two specific manufacturing industries, in Sweden and Finland. Since the structure of customer-supplier relationships is potentially an influence on the development of NCWs, the restriction to a single business sector must be treated as a potential limitation on the more general applicability of the findings. Furthermore, given the quite stable relationship networks applying in that context, the NCWs described by our respondents may have a different character from those in other business environments in which the dissolution of a relationship is relatively easy and could quickly release energy from the wave.

Because critical waves are conceptualised as socially constructed phenomena, the strategy for data collection was retrospective: interpretation and analysis of the narratives of executives and operatives recalling relevant past experiences. This qualitative approach achieved richness of data but placed limits on objectivity and hence on the scope for generalisation. Third, although the respondents' narratives described 77 critical waves, the sample size further inhibits the drawing of general conclusions. 
A number of fruitful avenues for future research on the implications of NCWs in business relationships can be identified. First, future studies could examine the four key dimensions of a wave in greater detail, especially with regard to their interdependency. For example, it would be useful to devise a means of capturing the life of NCWs in different contexts in which the degree of turbulence varies. The importance of the energy level and the origin of the waves emphasised by the results of this study indicates a need for deeper understanding of the history of the relationship, the organizational context, the generator, and the temporal effects, all in relation to the energy of the wave. The time frame is also a fruitful topic for further study, in terms of the lifecycle of waves from genesis to demise. The nature of NCWs could also be further analysed with respect to their social, technical and economic dimensions, and the possible connection with the nature of the outcomes.

Lastly, research should be conducted in other contexts, such as services marketing or consumer marketing, to identify the effect of that broader context on the process of negative critical wave generation and development, and to assess the implications for management of the affected relationships.

\section{REFERENCES}

Beverland, M. and Lockshin, L. (2003), "A longitudinal study of customers' desired value change in business-to-business markets”. Industrial Marketing Management Vol. 32 No. 8, pp. 653-67.

Blodgett, J.G. and S.S. Tax. (1993), "The Effects of Distributive and Interactional Justice on Complainants? Repatronage Intentions and Negative Word-of-Mouth Intentions", Journal of Consumer Satisfaction, Dissatisfaction and Complaining Behavior, Vol. 6, pp. 100-10.

Chen, Z. (2006), Chinese retail buyer-seller initiation and maintenance of relationships, doctoral dissertation, Michigan State University, Ann Arbor, MI.

Dahlin, P., Fors, J., Havila, V. and Thilenius, P. (2005), "Netquakes - Describing effects of ending business relationships on business networks", Proceedings of the IMP Conference 2005, Rotterdam, Netherlands.

Derbaix, C and Pham, M.T. (1991). Affective reactions to consumption situations: a pilot investigation. Journal of Economic Psychology, Vol. 12 No. 2, pp. 325-55.

Dubois, A., Gadde, L-E. and Mattsson, L.G. (2003). Change and continuity in the supplier base: a case study of a manufacturing firm 1964-2002. Journal of Customer Behavior, Vol. 2 No. 3, pp. 409-32.

Edvardsson, B. (1988). Service quality in customer relationships: a study of critical incidents in mechanical engineering companies. The Service Industries Journal, Vol. 8 No. 4, pp. 427-45.

Edvardsson, B. and Roos, I. (2001). Critical incident techniques - towards a framework for analysing the criticality of critical incidents. International Journal of Service Industry Management, Vol. 12 No. 3, pp. 251-68. 
Edvardsson, B., Holmlund, M. and Strandvik, T., (2008), "Relationship Initiation in Business-toBusiness Professional Services", Industrial Marketing Management. Vol. 37 No. 3, pp. 339-50.

Edvardsson, B and Strandvik, T. (2000). Is a critical incident critical for a customer relationship?. Managing Service Quality, Vol. 10 No. 2, pp. 82-91.

Edvardsson, B. and Strandvik, T. (2009). Critical times in business relationships. European Business Review, Vol. 21 No 4, pp. 326-43.

Edwardson, M. (1998). Measuring consumer emotions in service encounters; an exploratory analysis. Australian Journal of Market Research, Vol. 6 No. 2, pp. 34-48.

Flanagan, J.C. (1954). The critical incident technique. Psychological Bulletin, Vol. 51 No. 4, pp. 327-58.

Flint, D.J., Woodruff, R.B. and Gardial, S.F. (2002). Exploring the phenomenon of customers' desired value change in a business-to-business context, Journal of Marketing, Vol. 66 No. 4, 10217.

Gergen, K.J. (1994), Realities and relationships: Soundings in Social Construction, Harvard University Press, Cambridge, MA.

Geersbro, J. and Ritter, T. (2013). Antecedents and consequences of sales representatives' relationship termination competence, Journal of Business \& Industrial Marketing, Vol. 28 No. 1.

Gremler, D.D. (2004). The critical incident technique in service research. Journal of Service Research, Vol. 7 No. 1, pp. 65-89.

Hackley, C.E. (1998). Social constructionism and research in marketing and advertising. Qualitative Market Research: An International Journal, Vol. 1 No. 3, pp. 125-31.

Halinen, A. and Tähtinen, J. (2002), Research on ending exchange relationships: a categorization, an assessment, and an outlook, Marketing Theory, Vol. 2 No. 2, pp. 165-88.

Havila, V. and Salmi, A. (2000), Spread of Change in Business Networks: An Empirical Study of Mergers and Acquisitions in the Graphic Industry, Journal of Strategic Marketing, Vol. 8 No. 2, pp. 105-19.

Havila, V. and Wilkinson, I. (2002). The principle of the conservation of business relationship energy: or many kinds of new beginnings. Industrial Marketing Management, Vol. 31 No. 3, pp. 191-203.

Hines, P., Holweg, M. and Sullivan, J. (2000). Waves, beaches, breakwaters and rip currents - A three-dimensional view of supply chain dynamics. International Journal of Physical Distribution \& Logistics Management, Vol. 30 No 10, pp. 827-46.

Holmlund, M (2004). Analyzing business relationships and distinguishing different interaction levels. Industrial Marketing Management, Vol. 33, No. 4, pp. 279-87.

Holmlund, M. and Strandvik, T. (2005a). Stress in business relationships. Journal of Business \& Industrial Marketing, Vol. 20, No. 1, pp. 12-22.

Holmlund, M. and Strandvik, T. (2005b). Exploring and managing negative incidents in business relationships. Journal of Consumer Behavior, Vol. 4, No. 2, pp. 227-50.

Keaveny, S. M. (1995). Customer Switching Behavior in Service Industries: An Explorative Study. Journal of Marketing, Vol. 59, April, pp. 71-82.

Kowalkowski, C. (2011). The service function as a holistic management concept. Journal of Business \& Industrial Marketing, Vol. 26, No. 7, pp. 484-92. 
Lamberg, J-A. and Parvinen, P. (2003). The river metaphor for strategic management. European Management Journal, Vol. 21 No. 5, pp. 549-57.

Marshall, R., Huan, T.C., Xu, Y. and Nam, I. (2011). Extending prospect theory cross-culturally by examining switching behavior in consumer and business-to-business contexts. Journal of Business Research, Vol. 64 No. 8, pp. 871-78.

Michalski, S. (2004). Types of customer relationship ending processes. Journal of Marketing Management, Vol. 20 No. 9-10, 977-99.

Olkkonen, R. and Tuominen, P. (2008). Fading configurations in inter-organizational relationships: a case study in the context of cultural sponsorship, Journal of Business \& Industrial Marketing, Vol. 23 No. 3, pp. 203-12.

Richins, M.L. (1983). Negative word-of-mouth by dissatisfied consumers: a pilot study. Journal of Marketing, Vol. 47, Winter, pp. 68-78.

Richins, M.L. (1987). A multivariate analysis of responses to dissatisfaction. Journal of the Academy of Marketing Science, Vol. 15, No. 3, pp. 24-31.

Richins, M.L. (1997). Measuring emotions in the consumption experience. Journal of Consumer Research, Vol. 24, No. 2, pp. 127-46.

Roos, I (1999), Switching Paths in Customer Relationships, published doctoral dissertation, Hanken School of Economics, Helsinki, Finland.

Roos, I. (2002). Methods of investigating critical incidents. Journal of Service Research, Vol. 4 No. 3, pp. 193-204.

Singh, J. (1990). Voice, exit, and negative word-of-mouth behaviors: an investigation across three service categories. Journal of the Academy of Marketing Science, Vol. 18, No. 1, pp. 1-15.

Strandvik, T. and Holmlund M. (2008). How to diagnose business-to-business relationships by mapping negative incidents. Journal of Marketing Management, Vol. 24, No. 3-4, pp. 361-81.

Tähtinen, J. (2002). The process of business relationship ending - its stages and actors. Journal of Market-Focused Management, Vol. 5, No. 1, pp. 331-53.

Tähtinen, J and Halinen, A. (2002), Research on ending exchange relationships: a categorization, assessment and outlook, Marketing Theory, Vol. 2 No. 2, pp. 165-88.

Tidström, A. and Hagberg-Andersson, A. (2012), Critical events in time and space when cooperation turns into competition in business relationships, Industrial Marketing Management, Vol. 41 No. 2, pp. 333-43.

Tikkanen, H. and Alajoutsijärvi, K. (2002). Customer satisfaction in industrial markets: opening up the concept. Journal of Business \& Industrial Marketing, Vol. 17 No. 1, pp. 25-42.

Voima, Päivi (2001), Negative Internal Critical-Incident Processes - Windows on Relationship Change, published doctoral dissertation, Hanken School of Economics, Helsinki, Finland.

Wieringa, J.E. and Verhoef, P.C. (2007). Understanding Customer Switching Behavior in a Liberalizing Service Market: An Exploratory Study. Journal of Service Research, Vol. 10 no. 2, pp. 174-86.

Wu, Fang and Cavusgil, S.T. (2006). Organizational learning, commitment, and joint value creation in interfirm relationships. Journal of Business Research, Vol. 59 No. 1, pp. 81-89. 


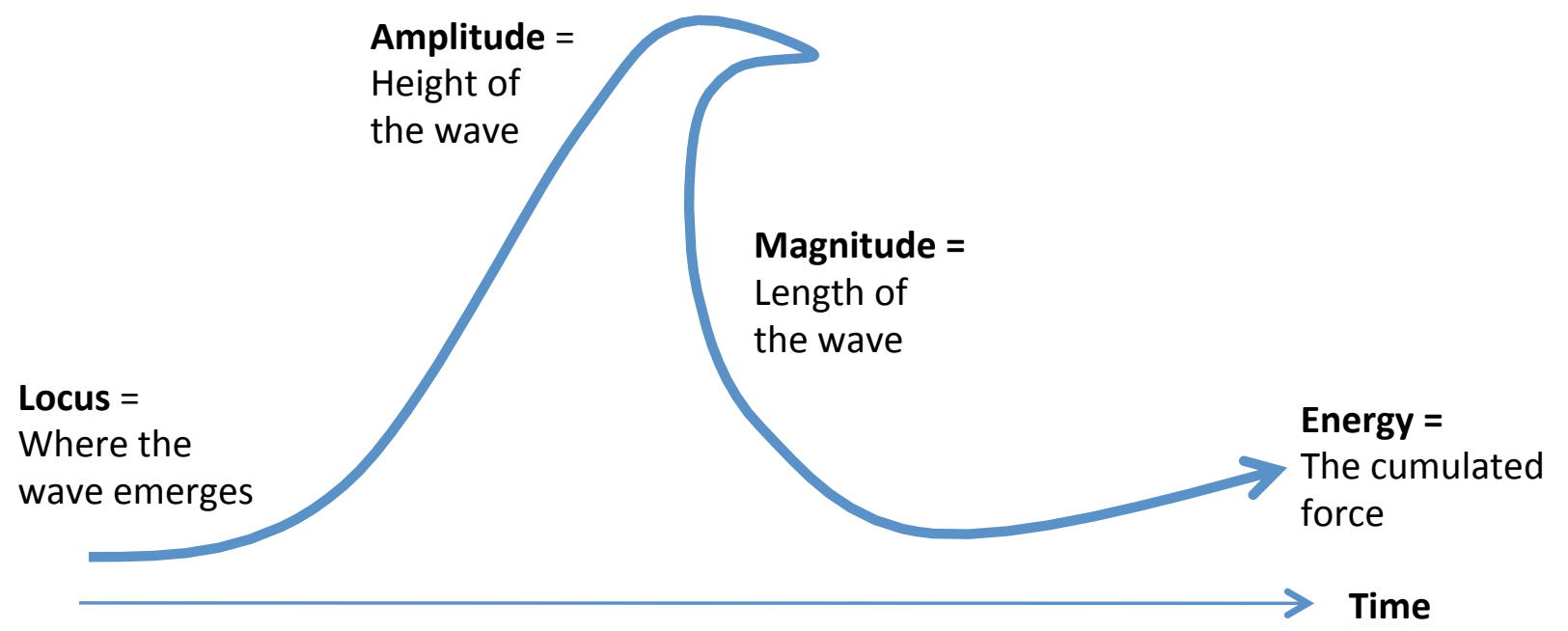

Figure 1. The formation of the negative critical wave.
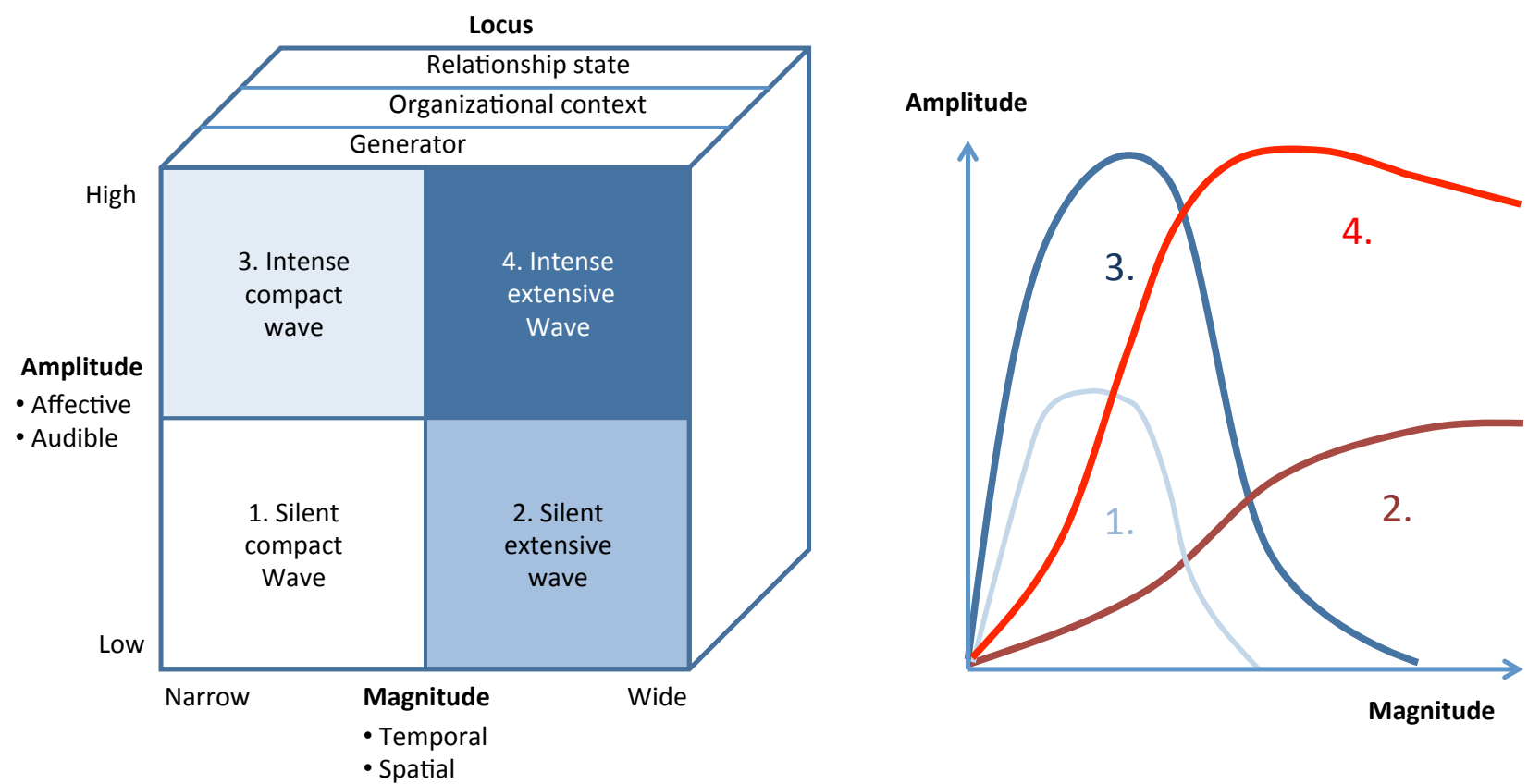

Figure 2. The negative critical wave model. 


\begin{tabular}{|c|c|c|}
\hline Factor & Category & Description \\
\hline Locus & $\begin{array}{l}\text { Initial state } \\
\text { Organizational context } \\
\text { Generator }\end{array}$ & $\begin{array}{l}\text { Refers to the condition of the relationship in which the NCW emerges } \\
\text { Refers to the organizational level in which the NCW emerges } \\
\text { Refers to the element(s) through which the NCW emerges }\end{array}$ \\
\hline Magnitude & $\begin{array}{l}\text { Temporal dimension } \\
\text { Spatial dimension }\end{array}$ & $\begin{array}{l}\text { Refers to the extension of time in which the NCW travels } \\
\text { Refers to the extension of space in which the NCW travels }\end{array}$ \\
\hline Amplitude & $\begin{array}{l}\text { Affective category } \\
\text { Communication category }\end{array}$ & $\begin{array}{l}\text { Refers to the level of emotions in the NCW } \\
\text { Refers to the level of communication within the NCW }\end{array}$ \\
\hline Energy & \multicolumn{2}{|c|}{ Refers to the cumulated force in the relationship and business system } \\
\hline
\end{tabular}

Table 1. Key determinants of the energy of a negative critical wave. 


\begin{tabular}{|c|c|c|c|c|c|c|}
\hline & Locus & & Magnitude & & Amplitude & \\
\hline \multirow[t]{2}{*}{$\begin{array}{l}\text { Silent } \\
\text { compact } \\
\text { wave }\end{array}$} & $\begin{array}{l}\text { Initial state: } \\
\text { Org.context: } \\
\text { Generator: }\end{array}$ & $\begin{array}{l}\text { Stable } \\
\text { Middle management } \\
\text { Technical (process) }\end{array}$ & $\begin{array}{l}\text { Temporal : } \\
\text { Spatial : }\end{array}$ & $\begin{array}{l}\text { Short-term } \\
\text { Narrow }\end{array}$ & $\begin{array}{l}\text { Affective: } \\
\text { Audible: }\end{array}$ & $\begin{array}{l}\text { Weak emotions } \\
\text { No } \\
\text { communication }\end{array}$ \\
\hline & $\begin{array}{l}\text { Initial state: } \\
\text { Org.context: } \\
\text { Generator: }\end{array}$ & $\begin{array}{l}\text { Unstable } \\
\text { Operational } \\
\text { Social (behavioral) }\end{array}$ & $\begin{array}{l}\text { Temporal : } \\
\text { Spatial : }\end{array}$ & $\begin{array}{l}\text { Short-term } \\
\text { (Long-term) } \\
\text { Narrow }\end{array}$ & $\begin{array}{l}\text { Affective: } \\
\text { Audible: }\end{array}$ & $\begin{array}{l}\text { High emotions } \\
\text { No } \\
\text { communication }\end{array}$ \\
\hline $\begin{array}{l}\text { Silent } \\
\text { extensive } \\
\text { wave }\end{array}$ & $\begin{array}{l}\text { Initial state: } \\
\text { Org.context: } \\
\text { Generator: }\end{array}$ & $\begin{array}{l}\text { Stable to unstable } \\
\text { Operational } \\
\text { Technical (process/ } \\
\text { communication) }\end{array}$ & $\begin{array}{l}\text { Temporal: } \\
\text { (Short-term) } \\
\text { Spatial : }\end{array}$ & $\begin{array}{l}\text { Long-term } \\
\text { Wide }\end{array}$ & $\begin{array}{l}\text { Affective: } \\
\text { Audible: }\end{array}$ & $\begin{array}{l}\text { Weak emotions } \\
\text { No/low level of } \\
\text { communication }\end{array}$ \\
\hline $\begin{array}{l}\text { Intense } \\
\text { compact } \\
\text { wave }\end{array}$ & $\begin{array}{l}\text { Initial state: } \\
\text { Org.context: } \\
\text { Generator: }\end{array}$ & $\begin{array}{l}\text { Unstable/turbulent } \\
\text { Middle management } \\
\text { Social (non-behavioral) } \\
\text { Technical (process/ } \\
\text { communication) }\end{array}$ & Spatial: & $\begin{array}{l}\text { Short-term } \\
\text { (Long-term) } \\
\text { Narrow }\end{array}$ & $\begin{array}{l}\text { Affective: } \\
\text { Audible: }\end{array}$ & $\begin{array}{l}\text { High emotions } \\
\text { Low level of } \\
\text { communication }\end{array}$ \\
\hline $\begin{array}{l}\text { Intense } \\
\text { extensive } \\
\text { wave }\end{array}$ & $\begin{array}{l}\text { Initial state: } \\
\text { Org.context: } \\
\text { Generator: }\end{array}$ & $\begin{array}{l}\text { Turbulent, unstable } \\
\text { Operational } \\
\text { Social (non-behavioral) } \\
\text { Technical (clock, } \\
\text { communication) }\end{array}$ & Temporal: & $\begin{array}{l}\text { Short-term } \\
\text { Long-term } \\
\text { Wide }\end{array}$ & $\begin{array}{l}\text { Affective: } \\
\text { Audible: }\end{array}$ & $\begin{array}{l}\text { High emotions } \\
\text { High level of } \\
\text { communication }\end{array}$ \\
\hline
\end{tabular}

Table 2. Detailed interpretations of the critical waves 